\title{
The relation between eating disorder symptoms and impairment
}

Article

Accepted Version

Jenkins, P. E., Rienecke, R. D., Conley, C. S., Meyer, C. and Blissett, J. M. (2015) The relation between eating disorder symptoms and impairment. Journal of Nervous and Mental Disease, 203 (6). pp. 452-458. ISSN 0022-3018 doi: https://doi.org/10.1097/NMD.0000000000000301 Available at https://centaur.reading.ac.uk/76089/

It is advisable to refer to the publisher's version if you intend to cite from the work. See Guidance on citing.

To link to this article DOI: http://dx.doi.org/10.1097/NMD.0000000000000301

Publisher: Lippincott, Williams \& Wilkins

All outputs in CentAUR are protected by Intellectual Property Rights law, including copyright law. Copyright and IPR is retained by the creators or other copyright holders. Terms and conditions for use of this material are defined in the End User Agreement.

\section{www.reading.ac.uk/centaur}

\section{CentAUR}

Central Archive at the University of Reading 
Reading's research outputs online 


\begin{abstract}
Although a number of studies have looked at what factors might mediate the relationship between symptoms and quality of life (QoL) in a number of psychiatric disorders, little research has addressed this issue in eating disorders. In the current study, female undergraduates $(\mathrm{N}=339)$ completed questionnaires assessing eating disorder symptoms, social support, coping, QoL, and psychosocial impairment. Perceived family support and levels of substance misuse as a way of coping were identified as mediators of the symptom-impairment relationship and, in addition, maladaptive coping also mediated the relationship with QoL. These results highlight the role of coping and social support in impairment resulting from eating disorder symptoms.
\end{abstract}

Keywords: Eating disorders; impairment; quality of life; social support; coping

\title{
Introduction
}

The scientific study of impairment resulting from eating disorder (ED) psychopathology has been increasing of late. As Bohn et al. (2008) note, EDs "have profound and specific effects on psychosocial functioning" (p. 1105) and a number of studies have described disorder-specific associations with impaired functioning, poor physical health, limitations in daily activities, and psychosocial stressors (e.g., Bamford et al., in press; Johnson, Spitzer, \& Williams, 2001; Striegel-Moore, Seeley, \& Lewinsohn, 2003; Wilfley, Wilson, \& Agras, 2003; see Jenkins, Hoste, Meyer, \& Blissett, 2011 for a review). Although there is some uncertainty regarding the specific profiles of impairment across diagnoses (DeJong et al., 2013), impairment 
has been demonstrated in full-syndrome and sub-threshold ED diagnoses (e.g., Stice, Marti, \& Rohde, 2013).

Treatment studies (e.g., Padierna, Quintana, Arostegui, Gonzalez, \& Horcajo, 2002) and longitudinal studies can provide further support for such findings. A recent longitudinal study by Wade, Wilksch, and Lee (2012) of a large community sample of Australian women found that even subclinical levels of symptoms are associated with lasting deficits in well-being. They found that disordered eating predicted later impairments in quality of life (QoL), spanning a period of nine years, although it was not possible to assess what proportion (if any) of these women had received treatment. The authors also highlight the need to look at variables that "might determine the strength of the relationship between disordered eating and QoL" (p. 354) as this has not yet been addressed empirically.

Although often used interchangeably, QoL is not the same as impairment (for a helpful delineation of QoL, health status, and functional impairment, see Ikeda, Hinckson, \& Krägeloh, 2014). As these areas have only been recently addressed in EDs, measures of both impairment and QoL have rarely been included together. Many studies have used generic measures of QoL, which have been criticised based on a possible lack of sensitivity to disorder-specific symptoms. However, in a study comparing generic and disease-specific measures of QoL in females with longstanding anorexia nervosa, Mitchison et al. (2013) found that a generic measure of QoL (the SF-12; Ware, Kosinski, \& Keller, 1996) adequately predicted changes in functional impairment and ED pathology, although this was limited to a small sub-sample of individuals with EDs. One prominent measure of impairment in EDs (the Clinical Impairment Assessment questionnaire; CIA, Bohn \& Fairburn, 2008) specifically aims to address impairment as a result of ED symptoms. 
The measure has been shown to correlate well with clinician ratings of impairment and degree of symptomatology, providing support that the CIA assesses impairment resulting from an ED (DeJong et al., 2013).

When considering variables that might affect the relationship between ED symptoms and impairment or QoL, social support is one possibility. Individuals with EDs have identified social support as lacking (Grissett \& Norvell, 1992) and its importance in coping with an ED has also been highlighted (Akey, Rintamaki, \& Kane, 2013; Bloks, van Furth, Callewaert, \& Hoek, 2004). In particular, perceived social support has been previously highlighted as important in patients' evaluations of their QoL (de la Rie, Noordenbos, Donker, \& van Furth, 2007), and social support has been shown to buffer the effects of symptoms of depression on functioning and QoL in other populations (e.g., Hays, Steffens, Flint, Bosworth, \& George, 2001; Rockhill, Vander Stoep, McCauley, \& Katon, 2009). Similarly, ED sufferers have identified social support as important in their recovery (e.g., Hsu, Crisp, \& Callender, 1992; Linville et al., 2012). Social support is a broad concept, encompassing emotional as well as practical support, and also covers both actual levels of social support, and perceived adequacy of that support (e.g., see Tiller et al., 1997). The role of perceived social support as a protective factor on QoL has been suggested in studies of both physical and mental illness (e.g., Manning-Walsh, 2005; Ritsner, Gibel, \& Ratner, 2006), and may have application to studies of ED symptoms.

In addition to social support, coping style may affect how ED symptoms influence impairment and QoL. Researchers have found that individuals with disordered eating tend to engage in coping that is inwardly-focused or avoidant in nature (e.g., Ball \& Lee, 2002), and that coping styles have also been found to be causally related to recovery (e.g., Bloks et al., 2004). Similarly, alcohol use has been 
associated with more negative consequences in individuals with EDs than controls, possibly linked to personality traits such as impulsivity and urgency, and may further exacerbate problems related to ED symptoms (Fischer, Smith, Annus, \& Hendricks, 2007). Thus, there is some reason to suspect that coping styles may operate in the relationship between ED symptoms and psychosocial impairment, being positively associated with both symptoms and impairment.

Models of mediation are one possible way of looking at relationships between the variables of ED symptoms and subsequent impairment. An independent variable (IV), for example psychiatric symptoms, is presumed to cause a dependent variable (DV), such as impairment. A mediator variable (e.g., social support) is one which accounts (at least partially) for the relation between the IV and the DV (Baron \& Kenny, 1986). One major difficulty with such models, however, is that they assume causality between the variables involved. Nonetheless, such methods can be useful in modelling relationships and exploring potential associations in detail.

The literature cited above, in particular longitudinal studies, suggests that ED symptoms are associated with subsequent impairment. Reducing impairment represents an important treatment aim (Bohn et al., 2008) and therefore, greater knowledge of factors that reduce the impact of ED symptoms on impairment is an important goal (Wade et al., 2012). Recent research has also looked at the predictive effect of symptoms on QoL (Ackard, Richter, Egan, Engel, \& Cronemeyer, 2014) and therefore it may be useful for studies to include measures of both impairment and QoL when considering the effects of ED symptomatology.

Few studies have yet considered what variables might affect QoL and impairment in eating pathology, and thus the purpose of the present study is to explore the mediational role of coping and social support in the relationship between 
symptoms of disordered eating and impairment and QoL. This model can be summarised in Figure 1, which includes a stressor (eating pathology), an outcome (psychosocial impairment or QoL), and social support and coping as potential mediators.

[Insert Figure 1]

\section{Methods}

\section{Participants and Procedure}

Three hundred and thirty-nine female Psychology undergraduates (male gender was an exclusion criterion) attending one of three universities in the UK or USA participated in the study and received course credit. They were invited by posters and advertisement at lectures, and those who provided informed consent were subsequently asked to complete self-report questionnaire packs. Individuals from the two countries did not differ across variables of body mass index (BMI), ED symptoms, psychosocial impairment, or QoL, and were considered as one sample (see Table 1). Limited demographic information was collected, although the majority (303/336; 90.2\%) identified English as their first language. Forty-nine (of 331 who responded; $14.8 \%$ ) had spoken to a health professional about concerns regarding eating, and a minority were either currently $(n=2 ; 1.0 \%)$ or previously $(n=9 ; 4.4 \%)$ in treatment, although 134 declined to provide this information. Mean (SD) age was 19.4 (2.2) years. The procedure was conducted in accordance with relevant ethical standards and approved by Ethics Review Boards at each site.

\section{Measures}


The Eating Disorder Examination - Questionnaire (EDE-Q; Fairburn \& Beglin, 1994) is a widely used self-report measure assessing both attitudinal and behavioural symptoms of an ED over the last 28 days, with good psychometric properties (Luce \& Crowther, 1999). It consists of four subscales ([Dietary] Restraint; Eating Concern; Shape Concern; Weight Concern), with scores ranging from $0-6$, with higher scores indicating more pathology. These can be averaged to form a composite score ('Global'), which has good support for its use as a measure of overall ED pathology (Friborg, Reas, Rosenvinge, \& Rø, 2013). Cronbach's alpha for the Global scale used in the current study was .95 .

The Multidimensional Scale of Perceived Social Support (MSPSS; Zimet, Dahlem, Zimet, \& Farley, 1988) is a 12-item questionnaire asking participants to indicate how much they agree with certain statements on a 7-point scale from very strongly disagree to very strongly agree. An example item is 'I can talk about problems with my family'. It assesses perceived social support, with higher scores indicating greater perceived support. Three subscales can be generated, representing sources of support: Family; Friends; and Significant Other. Good psychometric properties have been demonstrated across a range of samples (Zimet et al., 1990), and Cronbach's alpha for the subscales were as follows: Family 0.92; Friends 0.95; Significant Other 0.93 .

The Clinical Impairment Assessment questionnaire (CIA; Bohn \& Fairburn, 2008) is a self-report measure asking participants to respond to 16 items assessing psychosocial impairment due to ED features in the past month, beginning with a question "Over the past 28 days, to what extent have your eating habits, exercising, or feelings about your eating, shape, or weight...”. The items then follow (e.g., “...made you forgetful"), rated on a score of $0-3$ with options of "not at all," "a little," "quite 
a bit," and "a lot." A total score is calculated $(0-48)$ as long as at least 12 items have responses, with higher scores indicating greater impairment. Data from a number of studies suggest that the CIA is appropriate for use with EDs, demonstrating good psychometric properties (see Jenkins, 2013), with Cronbach's alpha of .91 in the current study.

The Medical Outcomes Study-Short Form Health Survey (Ware et al., 1996) is a 12-item self-report measure that assesses health-related quality of life. Two summary scores can be computed measuring physical health status (Physical Component Summary, PCS) and emotional health status (Mental Component Summary, MCS), used in the current study. Scores range from 0-100, with higher scores indicating better functioning. Extensive psychometric reports, including norms, have been provided (see Ware et al., 1996) and the measure has frequently been used as an index of QoL in EDs.

The Brief COPE (Carver, 1997) was used as a measure of how frequently participants used various coping strategies. Twenty-eight items (e.g., "I've been turning to work or other activities to take my mind off things") are rated on a $1-4$ frequency scale with higher scores indicating how often participants have used that specific coping strategy. Although Carver (1997) outlined a factor structure of 14 scales (i.e., of two items each), he also recommends that researchers use the measure flexibly, and therefore many studies using the Brief COPE have used principal components analysis (PCA) to determine the best fit for those data. PCA was conducted on the items to establish the best structure of coping for the sample under study (e.g., see Carver, Scheier, \& Weintraub, 1989). 
PCA was conducted with direct oblimin rotation to allow for correlation between factors and to identify underlying latent structures in the data. Communalities and determination of the factors (see MacCallum, Widaman, Zhang, \& Hong, 1999) suggested that the sample size was sufficient to produce a stable solution. KaiserMeyer-Olkin Measure of Sampling Adequacy was acceptable (.73) and Bartlett's test of sphericity was significant $(p<.001)$. The subject-to-item ratio was also acceptable. Items were retained on a factor if they loaded above 0.45 on one factor and below $0.45^{1}$ on other scales (see Tabachnick \& Fidell, 2007). Following the suggestions of Norris and Lecavalier (2010), a plot of eigenvalues (scree) and parallel analysis (O'Connor, 2000) suggested a 6-factor solution, which explained $57.44 \%$ of the variance. These factors were labelled as follows (with item numbers in parentheses): Engagement Coping (2, 7, 14, 20, 22, 25, 27); Social coping (5, 10, 15, 23); Jokes / Distraction (18, 19, 24, 28); Maladaptive Coping (6, 13, 16, 21, 26); Substance Use $(4,11)$; and Denial $(3,8)$, and then included in subsequent mediation analyses. Items 1 and 9 did not meet the requirements for factor loadings, and thus were not included. Items 12 and 17 ('Positive Reframing') were split between two factors (Engagement Coping and Jokes / Distraction) and were analysed separately, giving a total of seven coping styles. Item 16 was also split across two factors, but was included in Maladaptive Coping due to similarities with Item 6 and partial loading on this factor. Internal consistency estimates were acceptable for all subscales, although Denial (.63) and Jokes / Distraction (.64) in particular were lower than others.

Data analysis

\footnotetext{
${ }^{1}$ Item 6 had a loading of .445 , which was rounded up
} 
Analyses controlled for BMI due to associations with psychosocial impairment and ED symptoms (Hay, 2003). Adding history of treatment as an additional control variable did not change the results and so results are reported with only BMI as a covariate. Although many of the variables were non-normally distributed, nonparametric bootstrapping techniques were used as a statistical test of mediation, a practice which makes fewer assumptions, including normality of the sampling distribution of the indirect effect, than other inferential methods (see Hayes, 2013; Hayes \& Preacher, 2010; Preacher \& Hayes, 2004; 2008). Hayes (2013) has provided a macro ('PROCESS') for examining the effect of multiple mediators, based on OLS regression, which was used in the study and permitted all ten hypothesised mediators to be investigated (i.e., 3 subscales of the MSPSS and 7 coping styles from the Brief COPE). A resampling approach with bias-corrected bootstrapping procedure was used with 10,000 resamples to derive 95\% confidence intervals (CIs). Although an explanation of the bootstrapping procedure is outside the scope of the current paper, briefly, if the range between lower and upper CIs do not include zero then the null hypothesis is rejected (i.e., the effect is significantly different from zero at $p<.05$ ). All analyses were carried out using SPSS 17.0, adopting an $\alpha$ level of 0.05, and report direct (c') and indirect $(a b)$ effects, using unstandardised coefficients. Estimates of effect size cannot be generated in models with covariates (Hayes, 2013) and so are not reported.

\section{Results}

Mean scores and correlations are shown in Table 2. 
Greater ED symptoms are associated with higher scores on the Substance Misuse subscale $\left(a_{1}=0.14\right)$, which is associated with higher levels of reported impairment $\left(b_{1}\right.$ = 2.35), in line with hypotheses. Symptoms are also associated with lower MSPSSFamily scores $\left(a_{3}=-0.15\right)$, which are associated with lower CIA scores $\left(b_{5}=-0.79\right)$. Significant indirect effects were found for Substance Misuse $\left(a_{1} b_{1}=0.319 ; 95 \% \mathrm{CI}=\right.$ $0.127-0.602 ; \mathrm{SE}=0.121)$ and MSPSS-Family $\left(a_{3} b_{5}=0.119 ; 95 \% \mathrm{CI}=0.031-\right.$ 0.292; $\mathrm{SE}=0.062$ ) in the relationship between EDE-Q and CIA scores. The direct effect of ED symptoms on impairment (c') was also significant $(4.89 ; 95 \% \mathrm{CI}=4.406$ - 5.355; SE $=0.241$ ). The product of the coefficients (see Zhao et al., 2010) suggested complementary mediation (also known as 'partial mediation'; but see Hayes, 2013, pp. 170-172) for both paths (see Figure 1).

\section{Symptoms and $Q o L$}

Using MCS as an outcome measure, similar results were seen regarding the association of Substance Misuse and lower MCS scores $\left(b_{2}=2.71\right)$. EDE-Q scores were associated with higher Maladaptive Coping $\left(a_{2}=0.180\right)$, also associated with lower MCS scores $\left(b_{4}=-4.80\right)$. Higher levels of MSPSS-Family were associated with higher MCS scores $\left(b_{6}=1.31\right)$. Significant indirect effects were found for Substance Misuse $\left(a_{1} b_{2}=-0.372 ; 95 \% \mathrm{CI}=-0.810--0.119 ; \mathrm{SE}=0.169\right)$, Maladaptive Coping $\left(a_{2} b_{4}=-0.863 ; 95 \% \mathrm{CI}=-1.409--0.462 ; \mathrm{SE}=0.240\right)$, and MSPSS-Family $\left(a_{3} b_{6}=-\right.$ $0.195 ; 95 \% \mathrm{CI}=-0.471--0.031 ; \mathrm{SE}=0.109)$ in the relationship between EDE-Q and MCS scores. The direct effect was also significant $(-1.05 ; 95 \% \mathrm{CI}=-1.95--0.16$; $\mathrm{SE}$ $=0.46)$, suggesting complementary mediation for coping styles and competitive mediation for perceived family support (see Zhao et al., 2010). 
Using PCS as an outcome measure, Substance Misuse was associated with higher scores $\left(b_{3}=1.81\right)$ and was the only significant pathway, showing significant indirect effects $\left(a_{1} b_{3}=0.249 ; 95 \% \mathrm{CI}=0.067-0.563 ; \mathrm{SE}=0.121\right)$ in the relationship between EDE-Q and PCS scores. The direct effect of EDE-Q scores on PCS was not significant $(-0.112 ; 95 \% \mathrm{CI}=-0.69-0.47 ; \mathrm{SE}=0.29)$, suggesting indirect mediation .

\section{Discussion}

The present study tested the hypothesis that specific forms of coping and perceived social support mediate the relationship between ED symptoms and impairment (see Figure 1), finding evidence for complementary mediation in a sample of female university students. Complementary or competitive mediation in the presence of a significant direct effect suggests that other mediators may be present (Zhao et al., 2010); such variables might include personality traits (Fischer et al., 2007), anxiety, depression (Wade et al., 2012), employment status, and self-esteem (de la Rie et al., 2005).

Regarding social support, lower levels of perceived family support were found to mediate the relationship between ED symptoms and both impairment and mental health QoL (see Figure 1), but there was no role for mediation for perceived support from friends or significant others. This may reflect the relatively young age of participants, and is partially supported by findings that, for many college students, perceived support from family is strongly associated with well-being, even across cultures (e.g., Brannan et al., 2013). Interestingly, there was significant mediation pathway (and correlations) for perceived social support and impairment but not social coping (as measured by the Brief COPE), which might suggest that perceptions of social support were more important in this sample than actual support (e.g., Limbert, 
2010; see also Linville et al., 2012), although this conclusion is not definitive. There was no association with physical health QoL.

Although a number of coping styles were correlated with both ED symptoms and impairment, only Substance Misuse acted as a mediator in the relationship between symptoms and impairment. Use of substances as a way of coping also mediated the relationship between ED symptoms and mental health QoL, as did the subscale of Maladaptive Coping. These results partially support previous findings that individuals with ED pathology report more maladaptive coping than individuals with fewer symptoms (Ball \& Lee, 2002). Similarly, women with bulimia nervosa report more negative alcohol-related consequences (e.g., interpersonal, occupational) than peers without eating disorders, despite comparable levels of intake, which may partially be due to personality traits (Fischer et al., 2007). Similar studies may also represent a useful avenue for research regarding ED symptoms and impairment. Regarding physical health QoL, increased use of substances to cope was associated with higher scores, indicating better QoL.

There was corroboration between models including the CIA (a measure of impairment designed to exclude possible physical effects of an ED) and the MCS (a measure of mental health status), commensurate with findings that comorbid psychiatric illness and substance use is associated with lower QoL (e.g., Russo et al., 1997). It also provides partial support that generic measures of QoL perform well in ED samples (Mitchison et al., 2013; see also Ackard et al., 2014) although this was not a focus of the current study. However, the finding that substance use was positively associated with greater PCS scores (and no associations with social support) was unexpected and in contrast to the findings regarding mental health QoL. Use of substances has been found to be associated with MCS but not PCS scores 
(Salyers et al., 2000; see also Garg et al., 1999), so there may be different profiles associated with measures of mental health and physical health status respectively. A recent study by Ackard et al. (2014), for example, of women with EDs found that the MCS was more sensitive to differences associated with ED diagnostic classification than the PCS. Miller et al. (2013) found that hazardous alcohol use (although not substance use) was associated with lower MCS and higher PCS scores (using the SF12) in patients with bipolar disorder treated in primary care, concluding that there is a need to further understand the effects of comorbid substance use on QoL. The results of the current study suggest a need for further exploration of these issues within EDs.

A strength (but also potential drawback) of the coping measure used was the generation of subscales according to a latent variable structure; this method provides a detailed and idiosyncratic assessment of coping in the current sample, which is thus characteristic of this group, but might also limit generalisability. Notably, clustering of items was similar to other college samples (e.g., Feldman \& Hayes, 2005), supporting some consistency although some of the factors extracted had relatively poor levels of internal consistency; given the findings presented here, further research might seek to use measures of coping validated for the assessment of substance use in particular. Constraints of the current study include use of a cross-sectional, correlational design, which limits interpretation of causality among hypothesised pathways. It may be, for example, that the DV (impairment or QoL), causes changes in social support, violating an assumption of the methodology (Baron \& Kenny, 1986), or that individuals who report less impairment subsequently experience fewer symptoms (e.g., Brannan \& Petrie, 2011). Similarly, another construct (e.g., personality, trait anxiety) may act as a confounding variable, also referred to as epiphenomenonal association (Hayes, 2013), which accounts for the observed 
relationships between symptoms and impairment / QoL, and indeed some of the constructs under study (e.g., coping) may act as risk factors for eating pathology and may exacerbate impairment over time. The current study, in line with previous work, assumed a unidirectional relationship between ED symptoms and impairment / QoL; however, the converse to this relationship (that impairment affects levels of symptoms) may also be true, and this warrants investigation. It may be that coping, social support, ED symptoms, impairment, and QoL are closely interwoven (Ball \& Lee, 2002), and thus a number of reciprocal relationships exist. Although use of the CIA (which asks individuals to consider impairment occurring as a result of ED symptoms) allowed some degree of confidence that ED symptoms (both measured in the current study as occurring over the previous 28 days) preceded impairment, the design does not permit confirmation of the temporal occurrence of social support in this relationship (see Cole \& Maxwell, 2003) and thus results might best be considered as consistent with the mediational model suggested, but not proof thereof. More sophisticated testing of these hypotheses is required, as is exploration of similar (although not necessarily mutually exclusive) models, such as low social support predicting ED symptoms (e.g., Bodell et al., 2011), and inclusion of other samples (e.g., males, clinical EDs). The relationship between ED symptoms and impairment may be bidirectional ("reciprocal causation"; Hayes, 2013, p. 183), and so further exploration would be welcome; it may be, for example, that the mediators identified here also act as mediators in the reverse relationship. The high correlation between EDE-Q and CIA scores may also represent a limitation of the study, although this would be expected if symptoms are determinant factors of impairment (e.g., MartínezMartín et al., 2010) and is perhaps bolstered by the use of a generic QoL measure. Although there may be a conceptual overlap between ED symptoms and impairment, 
this correlation was taken as evidence of construct validity in the development of the CIA (Bohn et al., 2008).

In the current study, perceived family support was found to reduce the (negative) association between ED symptoms and impairment, whereas substance use increases it. This builds on previous work highlighting the importance of considering both social support and coping in ED pathology and may inform models of treatment, reiterating the importance of effective coping and the role of social relationships and continuation of improvement in areas beyond symptom recovery. Results may also inform interventions themselves, in that coping and social support should perhaps be assessed during treatment and directly modified if necessary. For example, interpersonal psychotherapy (IPT) has been identified as a major treatment for bulimic disorders (e.g., Agras, Walsh, Fairburn, Wilson, \& Kraemer, 2000). Based on the theory that interpersonal issues are a critical component of wellbeing (Arcelus, Whight, Brewin, \& McGrain, 2012), targets of treatment often include interpersonal disputes, communication training, and addressing social support networks (Fairburn, 1992; Mitchell, Agras, \& Wonderlich, 2007; Rieger et al., 2010). The findings of the current study suggest that stronger social support networks are associated with lower impairment resulting from ED pathology, and thus may offer support the use of models incorporating principles of IPT. Exploring these factors may also help individuals with EDs to better understand the broader context of the onset and maintenance of their illness.

\section{Conclusions}

Eating disorder symptoms are strongly associated with functional impairment and poor QoL. However, identifying variables associated with these relationships could 
reduce distress and improve treatment outcomes (Cook et al., 2013) and, as de la Rie and colleagues have argued (e.g., 2005), it is important to focus treatment on the patient as well as the disease. The current study reiterates the importance of social support and coping in ED pathology and suggests novel pathways, suggesting the role of mediators in the relationship between ED symptoms and impairment and QoL. Further work might seek to confirm causal directions in such relationships, as well as looking for other variables that might act as mediators, and perhaps also investigating more specific symptoms (e.g., binge eating, purging) and different diagnoses.

\section{Disclosures}

Dr. [name removed to preserve blind review] receives honoraria and consulting fees for training offered through the Training Institute for Child and Adolescent Eating Disorders. The remaining authors declare no conflicts of interest.

\section{References}

Ackard, D. M., Richter, S., Egan, A., Engel, S., \& Cronemeyer, C. L. (2014). The meaning of (quality of) life in patients with eating disorders: a comparison of generic and disease-specific measures across diagnosis and outcome. International Journal of Eating Disorders, 47, 259-267.

Agras, W. S., Walsh, B. T., Fairburn, C. G., Wilson, G. T., \& Kraemer, H. C. (2000). A multicenter comparison of cognitive-behavioral therapy and interpersonal psychotherapy for bulimia nervosa. Archives of General Psychiatry, 57, 459-466.

Akey, J. E., Rintamaki, L. S., Kane, T. L. (2013). Health Belief Model deterrents of social support seeking among people coping with eating disorders. Journal of Affective Disorders, 145, 246-52. 
Arcelus, J., Whight, D., Brewin, N., \& McGrain, L. (2012). A brief form of interpersonal psychotherapy for adult patients with bulimic disorders: a pilot study. European Eating Disorders Review, 20. 326-330.

Ball, K., \& Lee, C. (2002). Psychological stress, coping, and symptoms of disordered eating in a community sample of young Australian women. International Journal of Eating Disorders, 31, 71-81.

Bamford, B., Barras, C., Sly, R., Stiles-Shields, C., Touyz, S., Le Grange, D., et al. (in press). Eating disorder symptoms and quality of life: where should clinicians place their focus in severe and enduring anorexia nervosa? International Journal of Eating Disorders, doi: 10.1002/eat.22327

Baron, R. M., \& Kenny, D. A. (1986). The moderator-mediator variable distinction in social psychological research: Conceptual, strategic, and statistical considerations. Journal of Personality and Social Psychology, 51, 1173-1182.

Bloks, H., van Furth, E. F., Callewaert, I., \& Hoek, H. W. (2004). Coping strategies and recovery in patients with a severe eating disorder. Eating Disorders, 12, 157169.

Bohn, K., \& Fairburn, C. G. (2008). The Clinical Impairment Assessment questionnaire (CIA). In C. G. Fairburn (Ed.), Cognitive behavior therapy and eating disorders (pp. 315-317). New York: Guilford.

Bohn, K., Doll, H. A., Cooper, Z., O’Connor, M., Palmer, R. L., \& Fairburn, C. G. (2008). The measurement of impairment due to eating disorder psychopathology. Behaviour Research and Therapy, 46, 1105-1110.

Bodell, L. P., Smith, A. R., Holm-Denoma, J. M., Gordon, K. H., \& Joiner, T. E. (2011). The impact of perceived social support and negative life events on bulimic symptoms. Eating Behaviors, 12, 44-48. 
Brannan, D., Biswas-Diener, R., Mohr, C. D., Mortazavi, S., \& Stein, N. (2013). Friends and family: a cross-cultural investigation of social support and subjective well-being among college students. The Journal of Positive Psychology, 8(1), 6575.

Brannan, M. E., \& Petrie, T. A. (2011). Psychological well-being and the body dissatisfaction-bulimic symptomatology relationship: an examination of moderators. Eating Behaviors, 12, 233-41.

Carver, C. S. (1997). You want to measure coping but your protocol's too long: consider the Brief COPE. International Journal of Behavioral Medicine, 4(1), 92100.

Carver, C. S., Scheier, M. F., \& Weintraub, J. K. (1989). Assessing coping strategies: a theoretically based approach. Journal of Personality and Social Psychology, $56(2), 267-283$.

Cole, D. A., Maxwell, S. E. (2003). Testing mediational models with longitudinal data: questions and tips in the use of structural equation modeling. Journal of Abnormal Psychology, 112(4), 558-577.

Cook, B., Engel, S., Crosby, R., Hausenblas, H., Wonderlich, S., \& Mitchell, J. (2013). Pathological motivations for exercise and eating disorder specific healthrelated quality of life. International Journal of Eating Disorders. doi:10.1002/eat.22198.

de la Rie, S. M., Noordenbos, G., van Furth, E. F. (2005). Quality of life and eating disorders. Quality of Life Research, 14, 1511-1522.

de la Rie, S., Noordenbos, G., Donker, M., van Furth, E. (2007). The patient's view on quality of life and eating disorders. International Journal of Eating Disorders, $40,13-20$. 
DeJong, H., Oldershaw, A., Sternheim, L., Samarawickrema, N., Kenyon, M. D., Broadbent, H. et al. (2013). Quality of life in anorexia nervosa, bulimia nervosa and eating disorder not-otherwise-specified. Journal of Eating Disorders, 1, 43.

Fairburn, C. G. (1993). Interpersonal psychotherapy for bulimia nervosa: In G. L. Klerman \& M. M. Weissman (Eds), New Applications of Interpersonal Psychotherapy (pp. 353-378). Washington, DC: American Psychiatric Press.

Fairburn, C. G., \& Beglin, S. J. (1994). Assessment of eating disorders: Interview or self-report questionnaire? International Journal of Eating Disorders, 16, 363-370.

Feldman, G., \& Hayes, A. (2005). Preparing for problems: a measure of mental anticipatory processes. Journal of Research in Personality, 39(5), 487-516.

Fischer, S., Smith, G. T., Annus, A., \& Hendricks, M. (2007). The relationship of neuroticism and urgency to negative consequences of alcohol use in women with bulimic symptoms. Personality and Individual Differences, 43, 1199-1209.

Friborg, O., Reas, D. L., Rosenvinge, J. H., \& Rø, Ø. (2013). Core pathology of eating disorders as measured by the Eating Disorder Examination Questionnaire (EDE-Q): the predictive role of a nested general $(g)$ and primary factors. International Journal of Methods in Psychiatric Research, 22(3), 195-203.

Garg, N., Yates, W. R., Jones, R., Zhou, M., \& Williams, S. (1999). Effect of gender, treatment site and psychiatric comorbidity on quality of life outcomes in substance dependence. The American Journal On Addictions, 8, 44-54.

Grissett, N. I., Norvell, N. K. (1992). Perceived social support, social skills, and quality of relationships in bulimic women. Journal of Consulting and Clinical Psychology, 60, 293-299. 
Hay, P. (2003). Quality of life and bulimic eating disorder behaviours: Findings from a community-based sample. International Journal of Eating Disorders, 33, 434442.

Hayes, A. F. (2013). Introduction to mediation, moderation, and conditional process analysis: a regression-based approach. New York: Guilford Press.

Hayes, A. F., \& Preacher, K. J. (2010). Quantifying and testing indirect effects in simple mediation models when the constituent paths are nonlinear. Multivariate Behavioural Research, 45(4), 627-660.

Hays, J. C., Steffens, D. C., Flint, E. P., Bosworth, H. B., \& George, L. K. (2001). Does social support buffer functional decline in elderly patients with unipolar depression? The American Journal of Psychiatry, 158, 1850-1855.

Hsu, L. K. G., Crisp, A. H., \& Callender, J. S. (1992). Recovery in anorexia nervosa - the patient's perspective. International Journal of Eating Disorders, 11, 341350.

Ikeda, E., Hinckson, E., \& Krägeloh, C. (2014). Assessment of quality of life in children and youth with autism spectrum disorder: a critical review. Quality of Life Research, 23, 1069-1085. DOI: 10.1007/s11136-013-0591-6.

Jenkins, P. E. (2013). Psychometric validation of the Clinical Impairment Assessment in a UK eating disorder service. Eating Behaviors, 14, 241-243.

Jenkins, P. E., Hoste, R. R., Meyer, C., Blissett, J. M. (2011). Eating disorders and quality of life: a review of the literature. Clinical Psychology Review, 31, 113-121.

Johnson, J. G., Spitzer, R. L., \& Williams, J. B. W. (2001). Health problems, impairment and illnesses associated with bulimia nervosa and binge eating disorder among primary care and obstetric gynaecology patients. Psychological Medicine, 31(8), 1455-1466. 
Limbert, C. (2010). Perceptions of social support and eating disorder characteristics. Health Care for Women International, 31(2), 170-178.

Linville, D., Brown, T., Sturm, K., \& McDougal, T. (2012). Eating disorders and social support: perspectives of recovered individuals. Eating Disorders, 20, 216231.

Luce, K. H., \& Crowther, J. H. (1999). The reliability of the eating disorder examination-self-report questionnaire version (EDE-Q). International Journal of Eating Disorders, 25(3), 349-351. DOI: 10.1002/(SICI)1098108X(199904)25:3<349::AID-EAT15>3.0.CO;2-M

MacCallum, R. C., Widaman, K. F., Zhang, S., \& Hong, S. (1999). Sample size in factor analysis. Psychological Methods, 4(1), 84-99.

Manning-Walsh, J. (2005). Social support as a mediator between symptom distress and quality of life in women with breast cancer. Journal of Obstetric, Gynecologic \& Neonatal Nursing, 34(4), 482-493.

Martínez-Martín, P., Jiménez-Jiménez, F. J., Carroza García, E., Alonso-Navarro, H., Rubio, L., et al. (2010). Most of the Quality of Life in Essential Tremor Questionnaire (QUEST) psychometric properties resulted in satisfactory values. Journal of Clinical Epidemiology, 63, 767-773.

Miller, C. J., Abraham, K. M., Bajor, L. A., Lai, Z., Kim, H. M., et al. (2013). Quality of life among patients with bipolar disorder in primary care versus community mental health settings. Journal of Affective Disorders, 146(1), 100105.

Mitchell, J. E., Agras, W. S., \& Wonderlich, S. (2007). Treatment of bulimia nervosa: where are we and where are we going? International Journal of Eating Disorders, 40, 95-101. 
Mitchison, D., Hay, P., Engel, S., Crosby, R., Le Grange, D., et al. (2013).

Assessment of quality of life in people with severe and enduring anorexia nervosa: a comparison of generic and specific instruments. BMC Psychiatry, 13, 284.

Norris, M., \& Lecavalier, L. (2010). Evaluating the use of exploratory factor analysis in developmental disability psychological research. Journal of Autism and Developmental Disorders, 40, 8-20. DOI: 10.1007/s10803-009-0816-2.

O'Connor, B. P. (2000). SPSS and SAS programs for determining the number of components using parallel analysis and Velicer's MAP test. Behavior Research Methods, Instruments, \& Computers, 32(3), 396-402.

Padierna, A., Quintana, J. M., Arostegui, I., Gonzalez, N., \& Horcajo, M. J. (2002). Changes in health related quality of life among patients treated for eating disorders. Quality of Life Research, 11, 545-552.

Preacher, K. J., \& Hayes, A. F. (2004). SPSS and SAS procedures for estimating indirect effects in simple mediation models. Behavior Research Methods, Instruments \& Computers, 36(4), 717-731.

Preacher, K. J., Hayes, A. F. (2008). Asymptotic and resampling strategies for assessing and comparing indirect effects in multiple mediator models. Behavior Research Methods, 40, 879-891.

Rieger, E., Van Buren, D. J., Bishop, M., Tanofsky-Kraff, M., Welch, R., \& Wilfley, D. E. (2010). An eating disorder-specific model of interpersonal psychotherapy (IPT-ED): causal pathways and treatment implications. Clinical Psychology Review, 30, 400-410.

Ritsner, M., Gibel, A., Ratner, Y. (2006). Determinants of changes in perceived quality of life in the course of schizophrenia. Quality of Life Research, 15, 515-26. 
Rockhill, C. M., Vander Stoep, A., McCauley, E., \& Katon, W. J. (2009). Social competence and social support as mediators between comorbid depressive and conduct problems and functional outcomes in middle school students. Journal of Adolescence, 32(3), 535-553.

Russo, J., Roy-Byrne, P., Reeder, D., Alexander, M., Dwyer-O’Connor, E. D., et al. (1997). Longitudinal assessment of quality of life in acute psychiatric inpatients: reliability and validity. Journal of Nervous and Mental Disease, 185, 166-175.

Salyers, M. P., Bosworth, H., Swanson, J., Lamb-Pagone, J., \& Osher, F. (2000). Reliability and validity of the SF-12 Health Survey among people with severe mental illness. Medical Care, 38(11), 1141-1150.

Stice, E., Marti, C. N., \& Rohde, P. (2013). Prevalence, incidence, impairment, and course of the proposed DSM-5 eating disorder diagnoses in an 8-year prospective community study of young women. Journal of Abnormal Psychology, 122(2), $445-457$.

Striegel-Moore, R. H., Seeley, J. R., \& Lewinsohn, P. M. (2003). Psychosocial adjustment in young adulthood of young women who experience an eating disorder during adolescence. Journal of the American Academy of Child and Adolescent Psychiatry, 42(5), 587-593.

Tabachnick, B. G., \& Fidell, L. S. (2007). Using multivariate statistics (5 ${ }^{\text {th }}$ Ed.). Boston, MA: Pearson.

Tiller, J. M., Sloane, G., Schmidt, U., Troop, N., Power, M., \& Treasure, J. L. (1997). Social support in patients with anorexia nervosa and bulimia nervosa. International Journal of Eating Disorders, 21, 31-38. 
Wade, T. D., Wilksch, S. D., \& Lee, C. (2012). A longitudinal investigation of the impact of disordered eating on young women's quality of life. Health Psychology, $31,352-259$.

Ware, J. E. Jr., Kosinski, M., \& Keller, S. D. (1996). A 12-item short-form health survey: construction of scales and preliminary tests of reliability and validity. Medical Care, 34, 220-233.

Wilfley, D. E., Wilson, G. T., \& Agras, W. S. (2003). The clinical significance of binge eating disorder. International Journal of Eating Disorders, 34, S96-S106.

Zhao, X., Lynch, J. G. Jr., Chen, Q. (2010). Reconsidering Baron and Kenny: myths and truths about mediation analysis. Journal of Consumer Research, 37, 197-206.

Zimet, G. D., Dahlem, N. W., Zimet, S. G., Farley, G. K. (1988). The Multidimensional Scale of Perceived Social Support. Journal of Personality Assessment, 52, 30-41.

Zimet, G. D., Powell, S. S., Farley, G. K., Werkman, S., \& Berkoff, K. A. (1990). Psychometric characteristics of the Multidimensional Scale of Perceived Social Support. Journal of Personality Assessment, 55, 610-617.

DOI:10.1080/00223891.1990.967409. 
Table 1. Baseline clinical data of the sample.

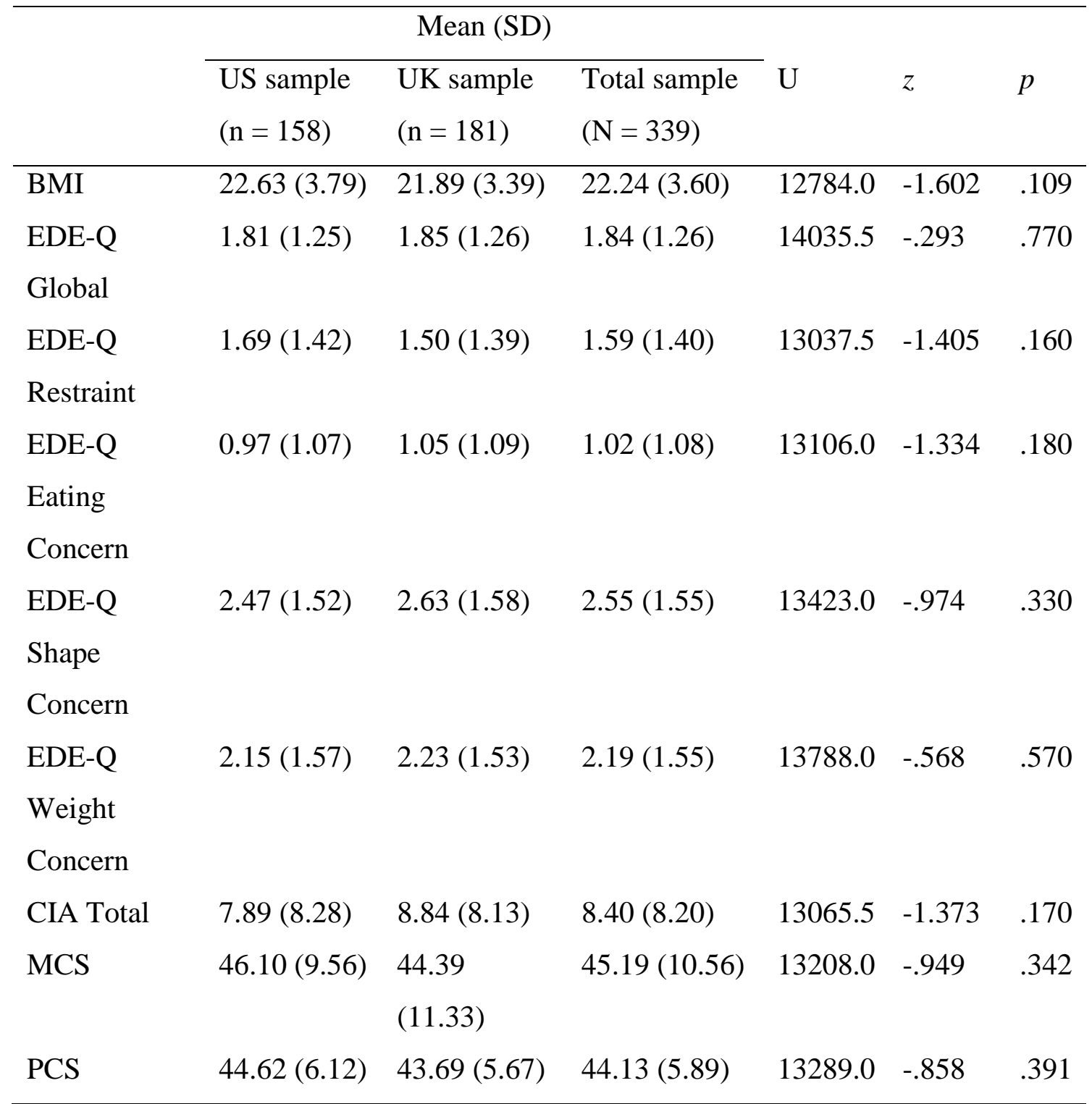

Note: $\mathrm{BMI}=$ body mass index; EDE-Q = Eating Disorder Examination - Questionnaire; CIA

$=$ Clinical Impairment Assessment questionnaire; MCS = Mental Component Summary; PCS

$=$ Physical Component Summary. 
Table 2. Correlation coefficients among BMI, measures of ED symptoms, impairment, QoL, social support, and coping (with descriptive statistics).

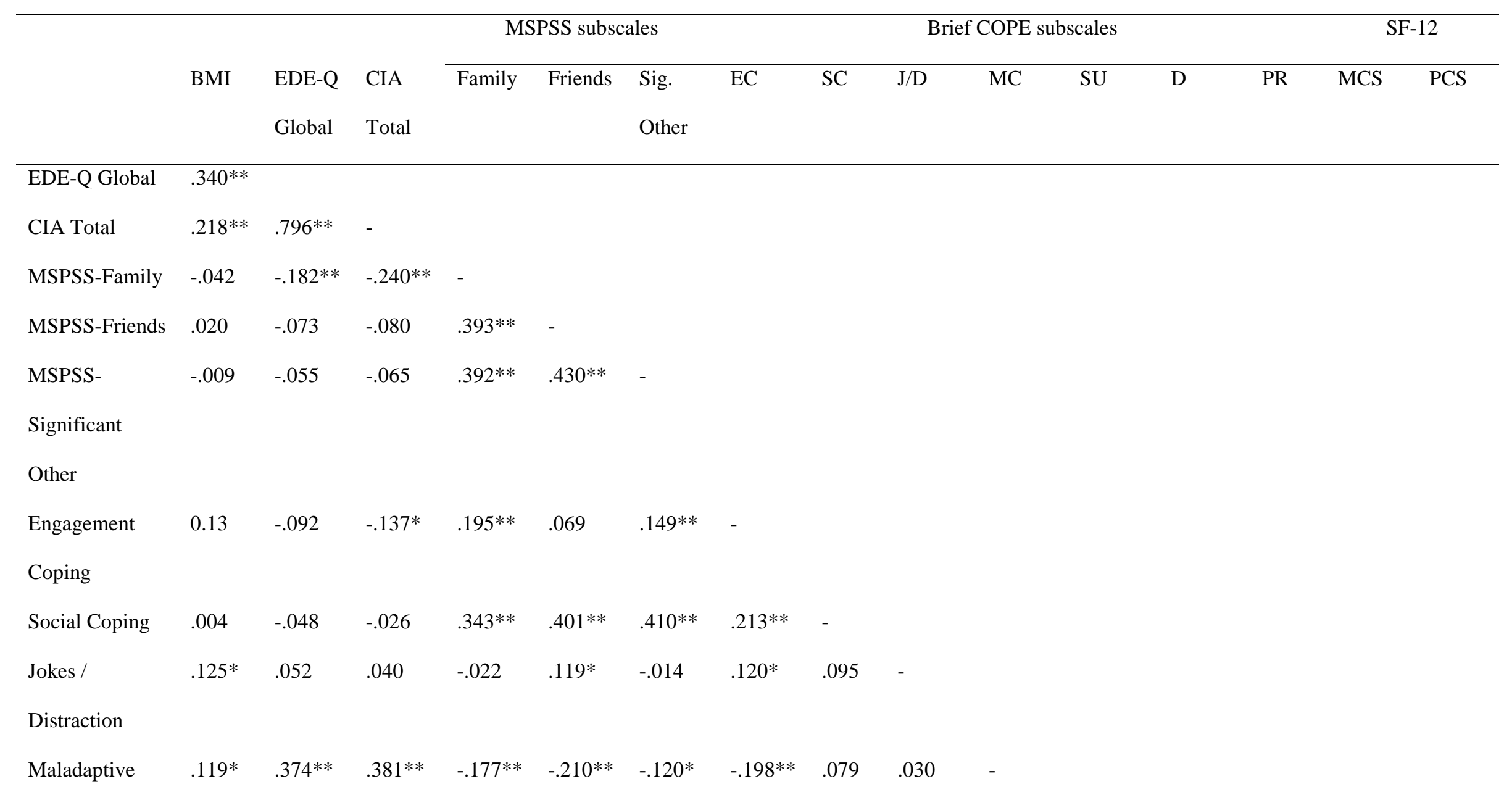




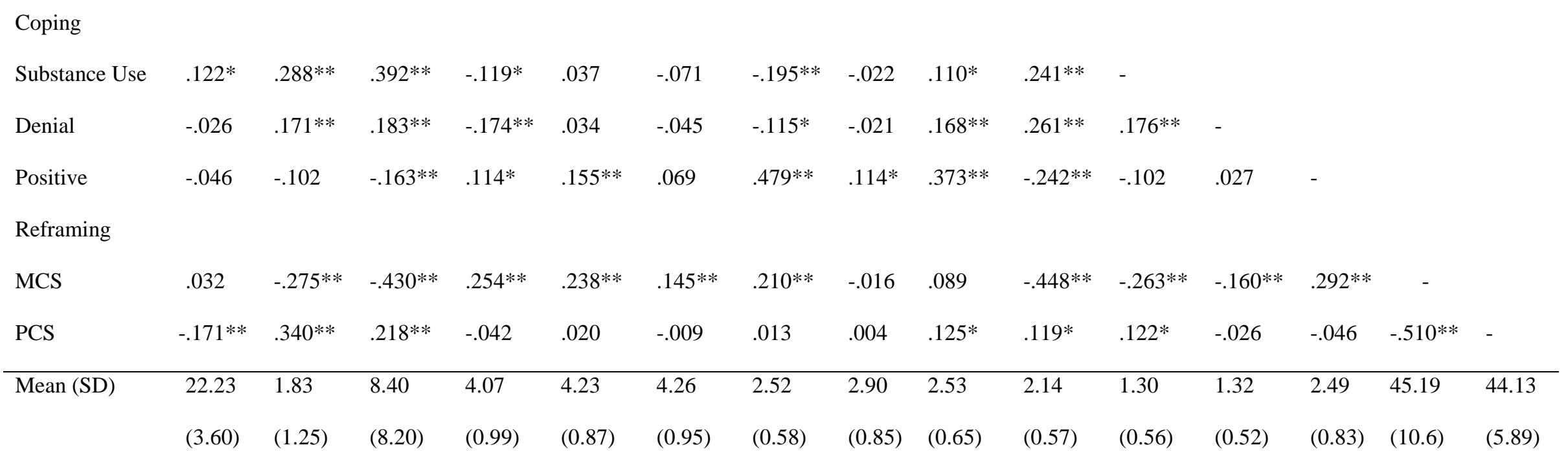

Note: BMI = body mass index; EDE-Q = Eating Disorder Examination - Questionnaire; CIA = Clinical Impairment Assessment questionnaire; MSPSS =

Multidimensional Scale of Perceived Social Support; MCS = Mental Component Summary; PCS = Physical Component Summary. ** $p<.01 * p<.05$ 
Figure 1. Model showing mediation by social support and coping on the relationship between ED psychopathology and impairment and QoL. The hypothesised direct effect (c') and indirect effects $(a, b)$ are shown (see text for details). 